\title{
Study of left ventricular pressure-volume relations during nitroprusside infusion in human subjects without coronary artery disease ${ }^{1}$
}

\author{
J. P. MERillon, G. MOTTE, M. C. AUMONT, R. PRASQUiER, AND \\ R. GOURGON
}

From Service de Cardiologie, Hôpital Beaujon, 100 Boulevard du Général Leclerc-92118 Clichy Cedex, France

SUMMARY Studies were made on 21 patients, 8 without any symptoms of left ventricular failure, group 1 , and 13 with clinical symptoms of heart failure, group 2. Cardiac output, mean aortic and left ventricular pressures (using catheter tip micromanometer), and ventricular volume (obtained from left ventricular cineangiograms) were measured before and during nitroprusside infusion. The heart rate did not change in either of the groups. Only in group 2 did cardiac index and stroke volume increase significantly. Mean aortic pressure and total systemic vascular resistance decreased significantly in both the groups. Left ventricular end-diastolic pressure decreased significantly in both the groups, but this decrease was greater in group 2 ( $9 \mathrm{mmHg}$ compared with $3 \mathrm{mmHg}$ for group 1). The decrease in the left ventricular end-diastolic volume was similar in both the groups. The decrease in left ventricular end-systolic pressure was greater in group 1, but the decrease in the left ventricular end-systolic volume was greater in group 2.

These facts are explained by the differences in the active and passive left ventricular pressure-volume relations in the two groups.

Many reports (Franciosa et al., 1972; Chatterjee et al., 1973; Miller et al., 1975; Rossen et al., 1976) have shown that vasodilator therapy is effective in acute and chronic left ventricular failure. Though it leads consistently to a decrease in aortic pressure, systemic vascular resistance, and left ventricular filling pressure, the changes in cardiac output have been less uniform.

The purpose of this study was to analyse the left ventricular pressure-volume diagram before and during nitroprusside infusion and to elucidate the effects of nitroprusside on cardiac output.

\section{Subjects and methods}

After obtaining informed consent, the haemodynamic and the angiographic changes before and during nitroprusside infusion were studied in 21 patients. These were 16 men and 5 women (the age range was from 23 to 63 years). All the patients were in regular sinus rhythm. None had valvular heart

${ }^{1}$ Work supported by DGRST.

Received for publication 30 January 1978 disease, septal defects, or left bundle-branch block, nor were there any clinical or electrocardiographic signs of coronary artery disease.

The patients were grouped in two categories. Group 1 comprised 8 patients who had never had symptoms of heart failure. Four had a primary hyperkinetic heart syndrome (Guazzi et al., 1975). Group 2 consisted of 13 patients all of whom were in cardiac failure. Some were on diuretic therapy, but no patient was taking digitalis. All had idiopathic cardiomyopathy.

The haemodynamic data recorded before and during nitroprusside therapy were as follows. (1) Cardiac output ( $\mathrm{CO}=1 / \mathrm{min})$ measured by the indocyanine green dilution technique: the dye was injected into the right atrium and sampled in the main pulmonary artery through a $7 \mathrm{~F}$ Swan-Ganz catheter. Cardiac index (CI) and stroke volume (SV) were calculated as follows:

$\mathrm{CI}=\frac{\mathrm{CO}}{\mathrm{BSA}}\left(1 / \mathrm{min}\right.$ per $\left.\mathrm{m}^{2}\right)$, where $\mathrm{BSA}$ is body surface area. $\mathrm{SV}=\frac{\mathrm{CO}}{\mathrm{HR}}(\mathrm{ml})$ where $\mathrm{HR}$ is heart rate. 
Table Haemodynamic data before $(C)$ and during $(N)$ nitroprusside infusion

\begin{tabular}{|c|c|c|c|c|c|c|c|c|c|c|c|c|c|c|c|}
\hline & \multirow{2}{*}{$\begin{array}{l}H R / \\
\min \\
C\end{array}$} & \multirow[b]{2}{*}{$N$} & \multicolumn{2}{|c|}{$\begin{array}{l}C I \\
\left(l / m i n \text { per } m^{2}\right)\end{array}$} & \multicolumn{2}{|c|}{$\begin{array}{l}S V \text { dye } \\
(m l)\end{array}$} & \multicolumn{2}{|l|}{$\begin{array}{l}S V A \\
(m l)\end{array}$} & \multicolumn{2}{|c|}{$\begin{array}{l}\overline{M A P} \\
(m m H g)\end{array}$} & \multicolumn{2}{|c|}{$\begin{array}{c}T S V R \\
\text { dyne } \mathrm{s}^{-1} \mathrm{~cm}^{-5}\end{array}$} & \multicolumn{2}{|c|}{$\begin{array}{l}\text { LVEDP } \\
(m m H g)\end{array}$} & $\frac{\Omega}{0}$ \\
\hline & & & $C$ & $N$ & $C$ & $N$ & $C$ & $N$ & $C$ & $N$ & $C$ & $N$ & $C$ & $N$ & Ds \\
\hline \multicolumn{16}{|l|}{ Group 1} \\
\hline 1 & 100 & 92 & $4 \cdot 8$ & 4.5 & 68 & 68 & 69 & 71 & 160 & 120 & 1882 & 1523 & 8 & 4 & ש \\
\hline 2 & 80 & 80 & $3 \cdot 7$ & $4 \cdot 1$ & 76 & 82 & 77 & 84 & 100 & 84 & 1311 & 1018 & 8 & 6 & $\omega$ \\
\hline 3 & 65 & 70 & $2 \cdot 8$ & $3 \cdot 1$ & 69 & 65 & 62 & 62 & 86 & 65 & 1528 & 1040 & 8 & 3 & $\rightarrow$ \\
\hline 4 & 70 & 65 & $3 \cdot 3$ & 3.5 & 85 & 86 & 91 & 82 & 88 & 60 & 1315 & 858 & 6 & 4 & \\
\hline 5 & 75 & 95 & $3 \cdot 8$ & $4 \cdot 3$ & 100 & 90 & 105 & 72 & 93 & 78 & 992 & 734 & 6 & 3 & \\
\hline 6 & 110 & 120 & 6.0 & $6 \cdot 0$ & 72 & 67 & 60 & 56 & 90 & 80 & 900 & 790 & 6 & 4 & \\
\hline 7 & 70 & 80 & 4.0 & 3.5 & 93 & 71 & 73 & 63 & 100 & 70 & 1240 & 982 & 4 & 1 & $\sigma$ \\
\hline 8 & 60 & 70 & $4 \cdot 2$ & $3 \cdot 7$ & 140 & 104 & 155 & 84 & 80 & 70 & 766 & 767 & 10 & 4 & \\
\hline Mean & 78 & 84 & $4 \cdot 1$ & $4 \cdot 1$ & 88 & 79 & 86 & 72 & 100 & 78 & 1241 & 964 & 7 & 4 & \\
\hline$\stackrel{ \pm}{\text { SE }}$ & $\pm_{17}$ & $\pm_{17}$ & $\stackrel{ \pm}{0.9}$ & $\stackrel{ \pm}{0.9}$ & $\frac{ \pm}{24}$ & \pm & $\pm \frac{1}{31}$ & \pm & \pm & $\pm_{18}$ & $\pm_{360}$ & $\stackrel{ \pm}{255}$ & \pm & \pm & \\
\hline $\begin{array}{l}\text { P value } \\
\text { Group } 2\end{array}$ & NS & & NS & & NS & & NS & & $\mathbf{P}<$ & & $\mathbf{P}<0$ & & $\mathbf{P}^{2}<$ & $001^{1}$ & \\
\hline 9 & 115 & 110 & $2 \cdot 2$ & $3 \cdot 1$ & 34 & 50 & 22 & 47 & 90 & 84 & 1800 & 1221 & 30 & 22 & \\
\hline 10 & 90 & 90 & $1 \cdot 7$ & $2 \cdot 0$ & 31 & 37 & 50 & 50 & 80 & 68 & 2245 & 1600 & 10 & 6 & \\
\hline 11 & 70 & 68 & 2.6 & $2 \cdot 6$ & 65 & 67 & 54 & 53 & 80 & 64 & 1406 & 1120 & 20 & 6 & \\
\hline 12 & 90 & 90 & 1.9 & $1 \cdot 7$ & 36 & 36 & 50 & 40 & 108 & 76 & 2468 & 1842 & 18 & 8 & \\
\hline 13 & 84 & 82 & $2 \cdot 2$ & 2.5 & 48 & 57 & 40 & 40 & 65 & 50 & 1238 & 851 & 30 & 12 & \\
\hline 14 & 110 & 100 & $2 \cdot 0$ & $4 \cdot 2$ & 34 & 77 & 42 & 75 & 64 & 54 & 1365 & 561 & 32 & 20 & \\
\hline 15 & 61 & 70 & $2 \cdot 8$ & $2 \cdot 9$ & 67 & 60 & 52 & 53 & 70 & 58 & 1400 & 1325 & 4 & 2 & \\
\hline 16 & 90 & 85 & $2 \cdot 8$ & $2 \cdot 5$ & 66 & 63 & 73 & 62 & 84 & 60 & 1120 & 980 & 10 & 3 & \\
\hline 17 & 70 & 75 & 1.7 & $2 \cdot 8$ & 51 & 68 & 45 & 85 & 86 & 64 & 1911 & 994 & 10 & 4 & \\
\hline 18 & 92 & 100 & 1.6 & $1 \cdot 6$ & 39 & 39 & 40 & 47 & 76 & 70 & 1688 & 1435 & 16 & 8 & \\
\hline 19 & 90 & 95 & $2 \cdot 2$ & $2 \cdot 4$ & 34 & 36 & 28 & 40 & 88 & 74 & 2270 & 1741 & 10 & 4 & \\
\hline 20 & 110 & 105 & $1 \cdot 3$ & 2.5 & 21 & 43 & 27 & 77 & 68 & 55 & 3820 & 2985 & 26 & 12 & \\
\hline 21 & 100 & 100 & $2 \cdot 6$ & $2 \cdot 9$ & 49 & 56 & 43 & 59 & 100 & 88 & 1632 & 1530 & 8 & 2 & \\
\hline Mean & 90 & 90 & $2 \cdot 1$ & $2 \cdot 6$ & 44 & 53 & 43 & 56 & 81 & 67 & 1874 & 1399 & 17 & 8 & $=$ \\
\hline$\stackrel{ \pm}{S E}$ & \pm & \pm & $\stackrel{ \pm}{0.5}$ & $\stackrel{ \pm}{0.7}$ & $\pm_{15}$ & $\pm_{13}$ & $\pm_{13}$ & $\frac{ \pm}{15}$ & $\pm_{13}$ & $\pm_{11}$ & $\pm_{719}$ & $\pm_{601}$ & $\frac{ \pm}{10}$ & \pm & \\
\hline $\mathbf{P}$ value & NS & & $\mathbf{P}<$ & & $\mathbf{P}<$ & & $\mathbf{P}<$ & & $\mathbf{P}<$ & 001 & $\mathbf{P}<$ & .01 & $\mathbf{P}$ & 001 & \\
\hline
\end{tabular}

HR, heart rate; $\mathrm{CI}$, cardiac index; SV dye, stroke volume derived from dye dilution technique; SVA, angiographic stroke volume; $\overline{\mathrm{MAP}}$, mean $\overrightarrow{\mathrm{F}}$ pressure; TSVR, total systemic vascular resistance; LVEDP, left ventricular end-diastolic pressure; LVEDV, left ventricular end-diastolic LVESV, left ventricular end-systolic volume; EF, ejection fraction; LVESP, left ventricular end-systolic pressure; SE, standard error; NS, nificant; NP, nitroprusside.

(2) Left ventricular and ascending aortic pressures $(\mathrm{mmHg})$ were recorded using a catheter tip micromanometer (Millar $5 \mathrm{~F}$ ). (3) The left ventricular cineangiograms were performed in the frontal plane (50 frames $/ \mathrm{s})$. Left ventricular volumes were calculated using the area length method of Dodge et al. (1966) and a grid calibration technique. The first 3 to 5 beats after injection of contrast were used for volume calculations. The post-ectopic beats were excluded.

Aortic pressure was recorded at a paper speed of $500 \mathrm{~mm} / \mathrm{s}$ during the angiogram, using a micromanometer placed in the ascending aorta. A single unit manually controlled marker permitted simultaneous synchronised measurements of angiographic films and pressure tracings from the beginning of the injection phase. It was possible to obtain the following indices before and during vasodilator infusion. (1) The systolic portion of the left ventricular pressure volume relation. The left ventricular systolic pressure was accepted as identical to the aortic systolic pressure. (2) The variations in the instantaneous pressure-volume relation with time. Intervals were measured from the peak of the $\mathbf{R}$ wave of the electrocardiogram.

The end-diastolic point of the ventricular pressure-volume diagram was established from the angiographic end-diastolic volume and from the end-diastolic ventricular pressure (LVEDP) obtained immediately before angiography. In this pressure-volume diagram, the end-diastolic volume is the largest volume and the end-systolic volume (ESV) is the smallest volume. The end-systolic pressure (ESP) is the pressure related to end-systolic volume and not to the dicrotic notch.

We then calculated (a) total systemic vascular resistance thus: $\mathrm{TSVR}=\frac{\overline{\mathrm{MAP}} \times 80}{\mathrm{CO}}\left(\right.$ dyne s$\left.^{-1} \mathrm{~cm}^{-5}\right)$, where $\overline{\mathrm{MAP}}$ is mean aortic pressure $\mathrm{mmHg}$, and $\mathrm{CO}$ is cardiac output $1 / \mathrm{min}$, and (b) the left ventricular ejection fraction as: 


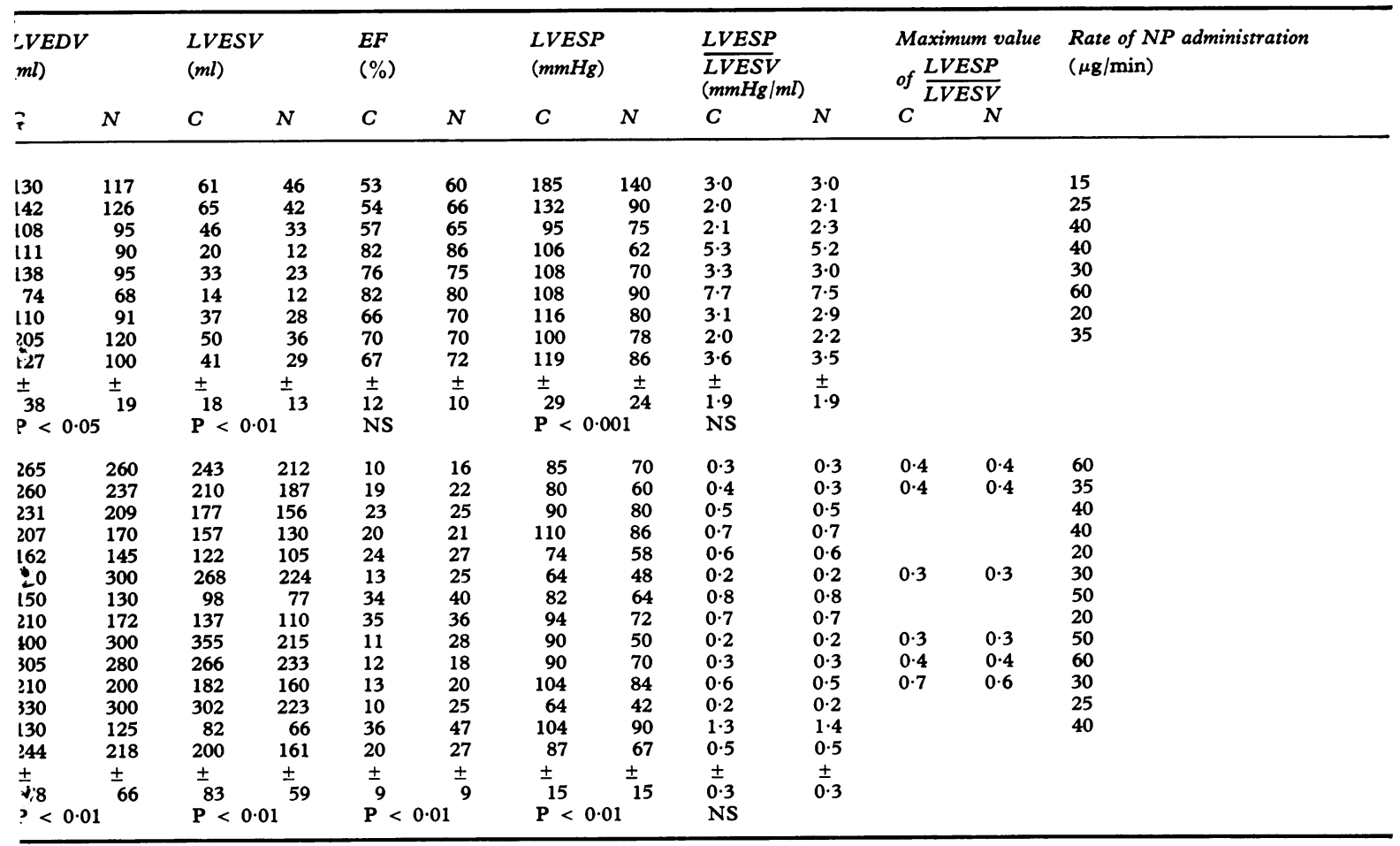

$$
\mathrm{EF} \%=\frac{\mathrm{SV}}{\mathrm{LVEDV}} \times 100 \text {, where } \mathrm{SV} \text { is }
$$

angiographic stroke volume (ml) and LVEDV is left ventricular end-diastolic volume $(\mathrm{ml})$.

Nitroprusside was infused by a flow controlled pump, 20 minutes after the first left ventricular angiogram. The initial flow rate was $10 \mu \mathrm{g} / \mathrm{min}$, and this was increased every 3 to 5 minutes to obtain a stable reduction of the mean aortic pressure. The reduction in the mean aortic pressure was less than $30 \mathrm{mmHg}$ except in 2 patients in whom the initial mean aortic pressure was above $100 \mathrm{mmHg}$. The simultaneous decrease of the left ventricular enddiastolic pressure was less than $10 \mathrm{mmHg}$ except in 4 patients in group 2 in whom the initial left ventricular end-diastolic pressure was above 20 $\mathrm{mmHg}$.

Once the pressures had become stable the nitroprusside infusion rate was maintained at a constant rate; this rate differed greatly in each patient (Table).

\section{Results}

(1) A good correlation was observed between the angiographically derived stroke volume and that obtained from the dye dilution method. The regression equation was: dye method $=6.9+0.89$ angio method ( $n=42, r=0.88$ ).

(2) Changes in heart rate, cardiac index, stroke volume, mean aortic pressure, total systemic vascular resistance, and ejection fraction. The heart rate did not change significantly in either group (Table). Significant increases in cardiac index and stroke volume were observed in group 2 only $(P<0.05)$. Mean aortic pressure and total systemic vascular resistance decreased significantly in both the groups (MAP group $1 \mathrm{P}<0.01$, and group $2 \mathrm{P}<0.001$; total systemic vascular resistance $P<0.01$ for both). The ejection fraction did not alter in group 1 , but it increased significantly in group $2(P<0.01)$.

(3) Changes in left ventricular end-diastolic pressure and volume. The end-diastolic pressure 


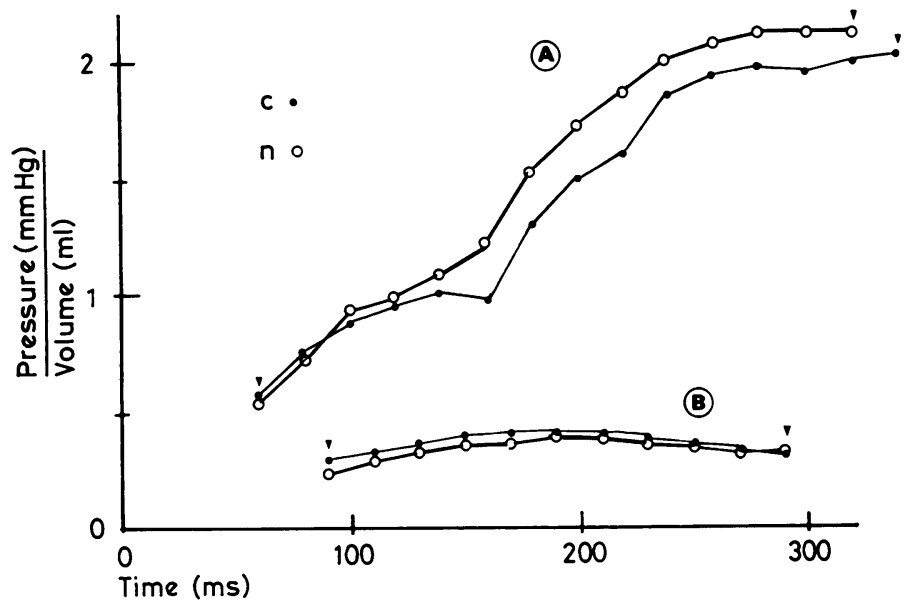

Fig. 1 Example of the instantaneous pressure-volume ratio plotted against time during ejection before (c) and during $(n)$ nitroprusside infusion in 2 patients. (A) Patient with a normal left ventricular performance. $(B)$ Patient with a cardiomyopathy. $\boldsymbol{\nabla}$, onset and end of ejection.

was lower in group 1 compared with group 2 $(P<0.01)$. In both groups it decreased significantly $(P<0.001)$, in group 1 by $3 \mathrm{mmHg}$ and in group 2 by $9 \mathrm{mmHg}$. The absolute decrease in group 2 was higher, but the relative decrease (that is percentage change from control) was identical in both groups. Left ventricular end-diastolic volume decreased significantly in both the groups (group $1 \mathrm{P}<0.05$; group $2 \mathrm{P}<0.01$ ). In terms of absolute value the decrease was the same in both groups $(27$ and $26 \mathrm{ml}$, respectively). The relative decrease was lower in patients in group $2(P<0.05)$ in whom the initial end-diastolic volume had been larger $(P<0.001)$.

(4) Changes in left ventricular end-systolic pressure and volume. Left ventricular end-systolic pressure decreased significantly in both the groups (group $1 \mathrm{P}<0.001$; group $2 \mathrm{P}<0.01$ ); the relative decrease was identical. In terms of absolute values the decrease was greater in group 1 than in group 2 (33 and $20 \mathrm{mmHg}$, repectively, $P<0.01$ ). The basal end-systolic pressure was higher in group 1 compared with group 2 ( $P<0.01)$.

Left ventricular end-systolic volume decreased significantly in both the groups ( $P<0.01$ for both), and the relative decrease was identical. In terms of absolute values the decrease was greater in group 2 compared with group 1 (39 and $12 \mathrm{ml}$, respectively, $P<0.05)$; the initial left ventricular end-systolic volume was higher in group $2(P<0.001)$.

Instantaneous systolic pressure-volume ratios during ventricular ejection were identical before and during nitroprusside infusion. Towards the end of systole, the pressure-volume ratio was practically constant (Fig. 1). Thus, even though ejection time

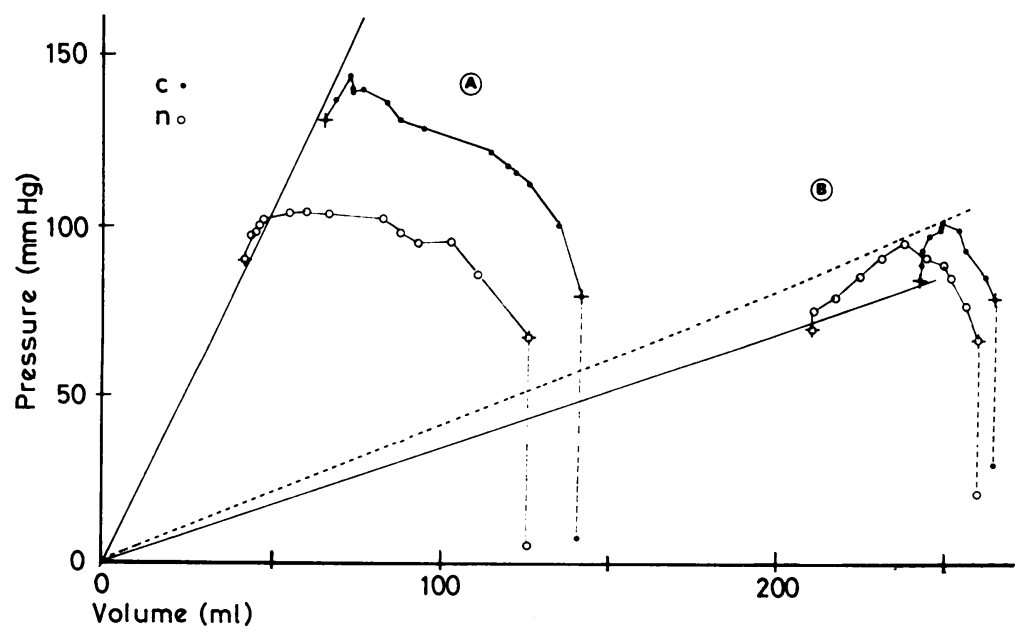

Fig. 2 Example of the left ventricular pressure-volume diagrams before $(c)$ and during $(n)$ nitroprusside infusion in 2 patients (same patients as Fig. 1). (A) Patient with a normal left ventricular performance. (B) Patient with a cardiomyopathy. + , onset and end of ejection. 
decreased slightly, during nitroprusside, the $\frac{\text { ESP }}{\text { ESV }}$ ratio remained constant (3.6 and 3.5 in group 1 ; 0.5 and 0.5 in group 2) (Table). In patients in group 2 the $\frac{E S P}{E S V}$ ratio was significantly lower compared with group 1 patients $(P<0.001)$.

As the $\frac{E S P}{E S V}$ ratio was nearly the same before and during vasodilator infusion, a straight line was obtained which intersected near the origin and on which the pressure-volume diagrams ended (Fig. 2). For all the patients in group 1 and for 7 in group 2 the $\frac{\text { ESP }}{\text { ESV }}$ relations corresponded to the maximum value of instantaneous pressure-volume ratio. For 6 patients in group 2, the $\frac{E S P}{E S V}$ ratio was lower than the maximum systolic value.

\section{Discussion}

Nitroprusside has no direct positive inotropic effects on the myocardium (Chatterjee et al., 1973). The effects of this agent in patients without coronary insufficiency are related to its peripheral effects on the arterial and venous systems and the resulting effects on the left ventricular loading conditions (Miller et al., 1975; Rossen et al., 1976).

The haemodynamic changes with nitroprusside in this study were similar to those reported previously. A drop in mean aortic pressure, left ventricular end-diastolic pressure, pulmonary wedge pressure, and systemic vascular resistance has been noted in normal subjects and in patients with arterial hypertension (Schlant et al., 1962), acute myocardial infarction (Franciosa et al., 1972; Chatterjee et al., 1973), and chronic congestive heart failure (Miller et al., 1975; Rossen et al., 1976). A significant increase in cardiac output was found mainly in patients whose left ventricular filling pressures were high in the control state, remaining at the upper limit of normal during vasodilator therapy (Chatterjee et al., 1973; Miller et al., 1975; Rossen et al., 1976). Conversely, if filling pressure decreased considerably a fall in cardiac output might result; this would be reversed by expansion of the circulating volume (Miller et al., 1975).

As there were only minor changes in heart rate, changes in cardiac output were accompanied by changes in stroke volume. The changes in stroke volume after nitroprusside followed closely the respective variations in end-diastolic volume and end-systolic volume.

During nitroprusside infusion there was a consistent decrease in left ventricular end-diastolic pressure and volume. In group 2, there was a similar reduction in left ventricular end-diastolic volume to that in patients in group 1 resulting in a larger decrease in end-diastolic pressure; this probably indicated that the patients in group 2, whose left ventricular end-diastolic pressure was higher, were on a steeper portion of the passive left ventricular pressure volume relation. However, our study does not allow evaluations of changes in left ventricular distensibility during nitroprusside infusion.

During nitroprusside infusion there was a consistent decrease in left ventricular end-systolic volume and pressure. In the patients in group 2, the decrease in end-systolic pressure was lower and the decrease in end-systolic volume was greater than in patients in group 1. This is explained by the fact that $\frac{E S P}{E S V}$ ratio remained constant before and during nitroprusside infusion, and also by the lower value of this ratio observed in patients in the second group.

For a given contractile state peak isovolumic pressure is linearly related to volume over the physiological range of ventricular volumes in the isolated dog heart, and the slope of this peak pressure-volume line becomes steeper as contractile state is enhanced. For the same contractile state and for the same range of ventricular end-diastolic volumes, the isolated left ventricle of the dog contracting auxotonically (that is with no isovolumic period, volume decreasing throughout systole) reaches a maximum value of the pressure-volume ratio at end-systole that lies on the same straight line as obtained by isovolumic contraction (Suga and Sagawa, 1974).

In human subjects it is impossible to obtain isovolumic pressure-volume data. Nevertheless in a preliminary study in human subjects we have shown that the end-systolic pressure-volume ratio was independent of loading changes and related to the inotropic state of the left ventricle (Merillon $e t$ al., 1977): the greater the end-systolic pressure volume ratio, the better the inotropic state.

Obviously stroke volume will increase only if end-systolic volume decreases more than enddiastolic volume. The decrease in left ventricular end-diastolic volume was similar in both groups. However as the slope of the end-systolic pressurevolume relation is lower in group 2, a slight decrease in left ventricular end-systolic pressure 
corresponds to a pronounced decrease in left ventricular end-systolic volume. Thus the stroke volume increased significantly only in patients from group 2.

We thank Dr R. Mathew for reading the manuscript.

\section{References}

Chatterjee, K., Parmley, W. W., Ganz, W., Forrester, J., Wolinsky, P., Crewells, C., and Swan, H. J. C. (1973). Hemodynamic and metabolic responses to vasodilator therapy in acute myocardial infarction. Circulation, 48, 1183-1193.

Dodge, H. T., Sandler, M., Baxley, W. A., and Hawley, R. R. (1966). Usefulness and limitations of radiographic methods for determining left ventricular volume. American fournal of Cardiology, 18, 10-24.

Franciosa, J. A., Guhia, N. H., Limas, C. J., Rodriguera, E., and Cohn, J. N. (1972). Improved left ventricular function during nitroprusside infusion in acute myocardial infarction. Lancet, 1, 650-654.

Guazzi, M., Fiorentini, C., Polese, A., Magrini, F., and Olivari, M. T. (1975). Stress induced and sympathetically- mediated electrocardiographic and circulatory variations in the primary hyperkinetic heart syndrome. Cardiovascular Research, 9, 342-354.

Merillon, J. P., Motte, G., Leclercq, J. F., Azancot, A., and Gourgon, R. (1977). Le rapport pression-volume ventriculaire, indice de performance ventriculaire gauche chez l'homme. Nouvelle Presse Médicale, 6, 1455-1457.

Miller, R. R., Vismara, L. A., Zelis, R., Amsterdam, E. A., and Mason, D. T. (1975). Clinical use of sodium nitroprusside in chronic ischemic heart disease. Circulation, 51, 328-336.

Rossen, R. M., Alderman, E. L., and Harrison, D. C. (1976). Circulatory response to vasodilator therapy in congestive cardiomyopathy. British Heart fournal, 38, 695-700.

Schlant, R. C., Tsagaris, T. S., and Robertson, R. J., Jr. (1962). Studies on the acute cardiovascular effects of intravenous sodium nitroprusside. American fournal of Cardiology, 9, 51-59.

Suga, H., and Sagawa, K. (1974). Instantaneous pressure volume relationships and their ratio in the excised supported left ventricle. Circulation Research, 35, 117-126.

Requests for reprints to Dr J. P. Merillon, Service de Cardiologie, Hôpital Beaujon, 100 Boulevard du Général-Leclerc, 92118 Clichy Cedex, France. 